IP Periodica Polytechnica Civil Engineering

59(3), pp. 405,411 2015

DOI: $10.3311 /$ PPci.7956

Creative Commons Attribution (1)

RESEARCH ARTICLE

\section{Rapid Stabilization of Sands with Deep Mixing Method Using Polyester}

\author{
Seracettin Arasan, Fatih Işık, R. Kağan Akbulut, A. Şahin Zaimoğlu, Omid Nasirpur
}

Received 06-02-2015, accepted 28-05-2015

\begin{abstract}
Rapid stabilization of weak soils is one of the important and current topics in geotechnical researches such as military application and stabilization of landslides. Deep mixing is an improvement method applied in the form of creating mixed columns which involves in-situ mixing of soil and lime or Portland cement with special equipment. The aim of this study was to evaluate the feasibility of utilizing polymers as a binder for rapid stabilization of sandy soils with deep mixing method. For this purpose, a series of unconfined compression tests were conducted on three different sandy soils improved with polyester. In the experiments, polyester was used at three different ratios of $10 \%, 20 \%$ and $30 \%$ and samples cured for 3 hour, 1, 3, 7 and 28 days. The laboratory test results of 3 hours samples showed that soils mixed with adequate polyester could reach a similar strength range of 28 days cured soils improved with cement or lime which was reported in the literature. The unconfined compressive strength increased with the increasing polyester ratio, effective diameter, and relative density and curing period, whereas, the changes on unconfined compressive strength were insignificant with the increase of freeze-thaw cycles. The overall evaluation of results has revealed that polyester is a good promise and a potential candidate for rapid deep mixing applications.
\end{abstract}

\section{Keywords}

Rapid stabilization $\cdot$ deep mixing $\cdot$ polyester $\cdot$ sand $\cdot$ unconfined compressive strength $\cdot$ freeze-thaw

\section{Seracettin Arasan}

Department of Civil engineering Faculty of Engineering, Ataturk University, Erzurum, Turkey

e-mail: arasan@atauni.edu.tr

\section{Fatih Işık}

\section{R. Kağan Akbulut}

Technical Vocational School of Higher Education, Ataturk University, Erzurum, Turkey

\section{A. Şahin Zaimoğlu \\ Omid Nasirpur}

Department of Civil engineering Faculty of Engineering, Ataturk University, Erzurum, Turkey

\section{Introduction}

Rapid stabilization of weak soils is one of the important and current topics in geotechnical researches such as military application and stabilization of landslides. Since World War II, the military has sought methods for rapid stabilization of weak soils in order to support its missions worldwide. Over the past 60 years, cement and lime have consistently been found to be among the most effective stabilizers for road and airfield applications (i.e., contingency airfield construction). However, recent developments on soil stabilization show the usability of polymeric materials [1]. Rapid stabilization is also needed for landslides and embankments applications. While many researches are focused on standard deep mixing applications, there is a limited number of studies in the literature on the rapid stabilization of soils with deep mixing. The developments show that the construction period can be accelerated in deep mixing applications where rapid stabilization is possible in a short time [2].

Deep mixing method is generally used for slope stability, embankment supports, hydraulic cut-off walls, excavation support walls, liquefaction mitigation, environmental remediation, in situ reinforcement and large volume ground treatment applications [3-6]. Deep mixing involves in-situ mixing of soil and binder materials with special equipment, frequently using rigs with counter rotating augers [7]. Lime and cement have been used as the primary binder material in deep mixing applications since 1970s, which have been extensively used worldwide. Commonly, two different techniques are utilized; column installation and slurry pressure injection. These techniques decrease soil moisture contents thereby reducing shrinkage/swelling and enhancing strength and compaction properties [3, 4, 8,-12].

The binder type and its ratio are the two important factors affecting deep mixing performance. A great number of experimental studies dealing with the effects of binder type and ratio on deep mixing method are available in the literature. Some of these studies focused on water/cement-lime $(w / c)$ ratio [13-31 and others dealt with curing period [32,33]. Most of the researchers pointed out that the unconfined compressive strength (UCS) increased when the $w / c$ ratio and curing time were increased. 
When compared to cement or lime, there is a limited number of studies in the literature on the utilization of waste materials in the improvement of soils using deep mixing method $[34-36]$. Silica fume, fly ash and slag are generally used with or without cement in deep mixing applications. The fly ash based mixture represents a cost effective alternative to conventional cement based mixture commonly in use. However, some previous research studies in this area demonstrated that many soil additives had little or no benefit for silty and sandy soil types. Sandy soils are problematic soils for stabilization and often require cement, asphalt emulsion or resins to bind the soil particles into a cohesive unit [37,38]. Therefore, some researchers focused on the stabilization of soils with polymers [39-45]. Although polymers are widely used in the industry, they are rarely used in soil stabilization applications. In this respect, some commercially available and non-traditional soil stabilization additives can be used as soil stabilization binder, such as emulsions, acids, lignin derivatives, enzymes, tree resins, and silicates. These binders may be in liquid or solid form and can be applicable for most soils [38].

Polyester is defined as condensation or step-growth polymers containing in-chain ester units as their essential polymerforming chain linkage [46]. Polyester has 18\% market share of all plastic materials and is widely used as thermoset plastic, fibre and fabric in many industries such as auto and marine body parts, building panels, clothing, carpet, furniture, etc. Thus remarkable researches have been done on polymer science [46, 47]. However, very limited information has been reported on the concrete technology [48, -51] and soil stabilization [52,53].

Loose sandy soils possess great potential of stability problems, such as landslides and liquefaction. Hence, studies on rapid stabilization of sandy soils with deep mixing method using polymers are important for geotechnical knowledge and practice. The present study was undertaken to investigate the effects of polyester on unconfined compressive strength and freezethaw properties of sandy soils at two different relative densities (i.e., $40 \%$ and $60 \%$ ) and five different curing periods (i.e. 3 hour, 1 day, 3 days, 7 days and 28 days). In the experimental study, sand was mixed with polyester (i.e. $10 \%, 20 \%$ and $30 \%$ by dry weight of sand). Some of the tests were repeated for three times to assure the repeatability of the results.

\section{Materials and Methods}

\subsection{Materials}

Natural sand was gathered from a sandy area near ErzincanTurkey. Three different sandy soils were prepared at sieve ranges of $1.18 \mathrm{~mm}-2.00 \mathrm{~mm}$ (i.e. $\mathrm{S} 1$ ), $0.6 \mathrm{~mm}-1.18 \mathrm{~mm}$ (i.e. $\mathrm{S} 2$ ) and $0.3 \mathrm{~mm}-0.6 \mathrm{~mm}$ (i.e. S3) for experiments. The geotechnical properties and grain size distributions of sandy soils are given in Table 1 and Fig. 1, respectively. In the experiments, unsaturated polyester (casting type), Cobalt Naphthenate and Methyl Ethyl Ketone Peroxide (MEKP) produced by Dewilux (Turkey) were used. Cobalt Naphthenate was used as accelerator, whereas, MEKP was used as catalyst. Some physical and chemical properties of mentioned chemicals obtained from manufactures are given in Table 2 Some previous studies indicated that Cobalt Naphthenate and MEKP should be used at the ratios of $2 \%$ and $0.4 \%$ (by the weight of polyester), respectively [52,53].

Tab. 1. Some geotechnical properties of sandy soils

\begin{tabular}{cccc}
\hline Properties & S1 & S2 & S3 \\
\hline Soil classification (USCS) & SP & SP & SP \\
\hline Specific gravity, $\mathrm{G}_{S}$ & 2.67 & 2.64 & 2.66 \\
\hline Max void ratio, & 0.90 & 0.97 & 1.00 \\
\hline Min void ratio, & 0.61 & 0.65 & 0.72 \\
\hline $\mathrm{D}_{10}, \mathrm{~mm}$ & 1.3 & 0.65 & 0.34 \\
\hline $\mathrm{D}_{30}, \mathrm{~mm}$ & 1.4 & 0.76 & 0.40 \\
\hline $\mathrm{D}_{60}, \mathrm{~mm}$ & 1.7 & 0.91 & 0.47 \\
\hline $\mathrm{C}_{u}$ & 1.31 & 1.40 & 1.38 \\
\hline $\mathrm{C}_{c}$ & 0.89 & 0.98 & 1.00 \\
\hline
\end{tabular}

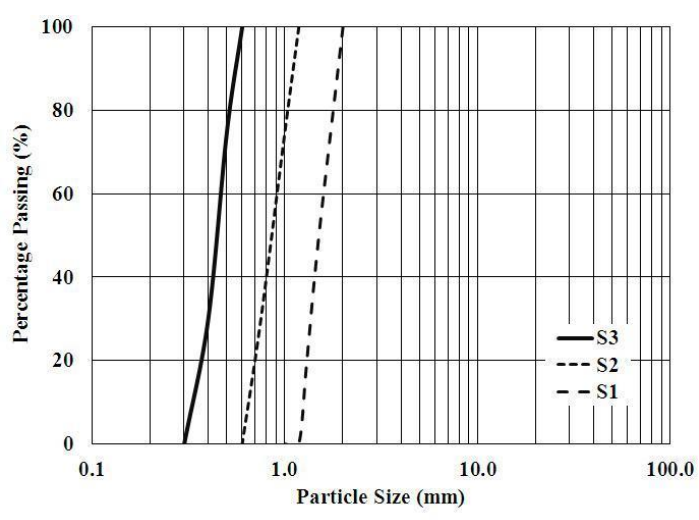

Fig. 1. Grain size distributions of sandy soils

\subsection{Specimen Preparation and Testing}

Polyester mixture was prepared by adding $2 \%$ Cobalt Naphthenate as accelerator and $0.4 \%$ MEKP as catalyst. Firstly, polyester and accelerator were mixed for a minute by hand and then catalyst was added and mixed for a minute by hand. Subsequently, the prepared polyester mixture was added to sand and mixed for 5 minutes using a $150 \mathrm{rpm}$ mechanical mixer. It should be noted that prepared "polyester mixtures" is named as "polyester" in the following sections. In the experiments, sand was mixed with polyester at the ratios of $10 \%, 20 \%$ and $30 \%$ by dry weight of sand. Test samples were prepared in accordance with the procedures described in JGS 0821 [54] and EuroSoilStab [55]. The prepared samples were then placed into metal cylinder moulds (i.e. each $38 \mathrm{~mm}$ in diameter and $76 \mathrm{~mm}$ in height) in three layers for achieving required relative densities. Inner sides of the moulds were lubricated to make the extrusion of the samples easier. In order to remove air bubbles, moulds were slightly vibrated. Prepared samples were cured in the moisture room where the temperature was kept at $20 \pm 3^{\circ} \mathrm{C}$ and relative humidity was $90 \%$. Curing periods of 3 hour, 1 day, 
Tab. 2. Some properties of polyester and chemicals

\begin{tabular}{|c|c|c|c|}
\hline Properties & Polyester & Accelerator & Catalyst \\
\hline Name & $\begin{array}{c}\text { Polyethlene } \\
\text { terephththalate }\end{array}$ & $\begin{array}{c}\text { Cobalt(II) } \\
\text { naphthenate }\end{array}$ & $\begin{array}{l}\text { 2-Hydroperoxy-2-((2 } \\
\text { hydroperoxybutan- } \\
\text { 2-yl)peroxy)butane }\end{array}$ \\
\hline Formula & $\left(\mathrm{C}_{10} \mathrm{H}_{8} \mathrm{O}_{4}\right)_{n}$ & $\mathrm{CoC}_{22} \mathrm{H}_{14} \mathrm{O}_{4}$ & $\mathrm{C}_{8} \mathrm{H}_{8} \mathrm{O}_{6}$ \\
\hline Color & Colorless & Bluish-red & Water white \\
\hline Solid Ratio & $65 \%$ & $6 \%\left(\mathrm{Co}^{+2}\right)$ & - \\
\hline Specific Gravity & 1.13 & 0.96 & 1.17 \\
\hline
\end{tabular}

3 days, 7 days and 28 days were determined to study the effect of curing periods on strength. The effect of relative density was also investigated. For this reason, samples were prepared at $40 \%$ and $60 \%$ relative densities. At the end of each curing period, they were exposed to unconfined compression strength (UCS) test. UCS tests were conducted according to ASTM D 2166. The testing load was applied at a rate of $0.5 \mathrm{~mm} /$ minute.

The freeze-thaw tests were performed by a programmable cabinet. It should be mentioned that only the 28 days cured samples were exposed to freeze-thaw test. The samples were placed in to the cabinet and conditioned at $-20^{\circ} \mathrm{C}$ for 6 hours. Then, they were thawed at $+25^{\circ} \mathrm{C}$ for 6 hours [56]. This process was named as "one cycle". All specimens were exposed to 20 freeze-thaw cycles.

\section{Results and Discussion}

In the following section, the effects of polyester ratio, curing periods and freeze-thaw effect on the unconfined compressive strength for sand samples are presented. Additionally, the findings from the experimental tests are compared with those from other studies in the literature and discussed.

\subsection{The effect of polyester ratio and curing periods}

The relationship between polyester ratio and UCS of 3 hours cured samples are given in Fig. 2. The UCS values of all reinforced samples increase with the increasing polyester ratio (Fig. 2). As can be seen in Fig. 2, the increment of UCS values between $10 \%$ and $20 \%$ is generally higher than the values between $20 \%$ and $30 \%$ polyester ratios. When the UCS strengths of the samples for 3 hours of curing time are compared, sample with the gradation range of $0.3 \mathrm{~mm}$ to $0.6 \mathrm{~mm}$ yielded the maximum value. The UCS values of this sample at $10 \%, 20 \%$ and $30 \%$ polyester ratios were obtained as 1.0, 5.8 and $6.5 \mathrm{MPa}$, respectively. On the other side, the sample of $1.18-2.00 \mathrm{~mm}$ at $40 \%$ relative density gave minimum UCS values for 3 hours curing period. The UCS values of this sample at $10 \%, 20 \%$ and $30 \%$ polyester ratios were obtained as $0.5,1.1$ and $1.3 \mathrm{MPa}$, respectively (Fig. 2). It should be also noted that the lowest UCS value obtained in this study is higher than that of the lower UCS limit of granular soil (i.e., 0.5 MPa) for deep mixing method reported by Bruce et al. [3] and Bruce and Bruce [4]. It can be concluded that polyester is a promising material to be used in deep mixing applications with an aim of rapid stabilization of granular soils.

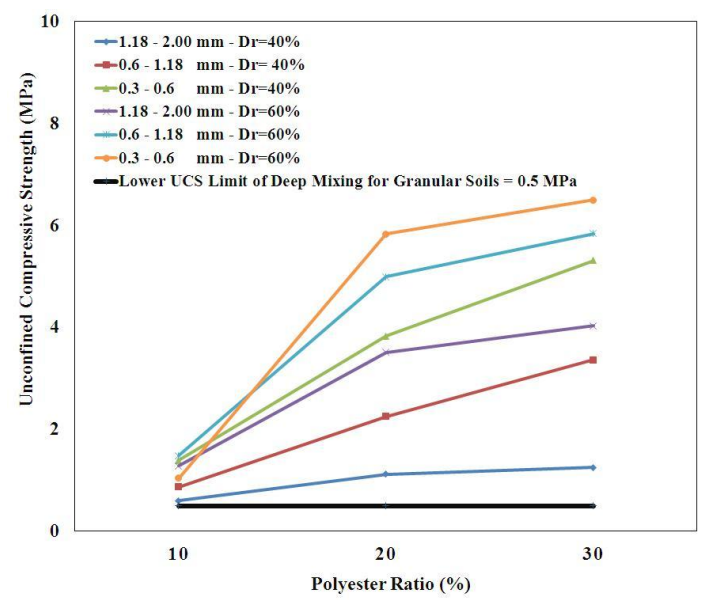

Fig. 2. UCS versus polyester ratio for 3 hours cured samples

The column graphs in 3-D are drawn to enable the investigation of the combined effects of polyester ratio and curing periods on UCS in Fig. 3 and Fig. 4 for $40 \%$ and $60 \%$ relative densities, respectively. It can be clearly seen in Fig. 3 and Fig. 4 that UCS values increase drastically after 3 hours curing period at each polyester ratios. Apparently, the UCS values of 3 hours cured samples have higher values than $0.5 \mathrm{MPa}$ (i.e., the lower UCS limit of granular soil). There is a significant increase in UCS values of $20 \%$ and $30 \%$ polyester ratios with an increase on curing periods (Fig. 3 and Fig. 4). However, the increase in the curing period has no important effect on the UCS values of $10 \%$ polyester samples especially after 1 day curing periods.

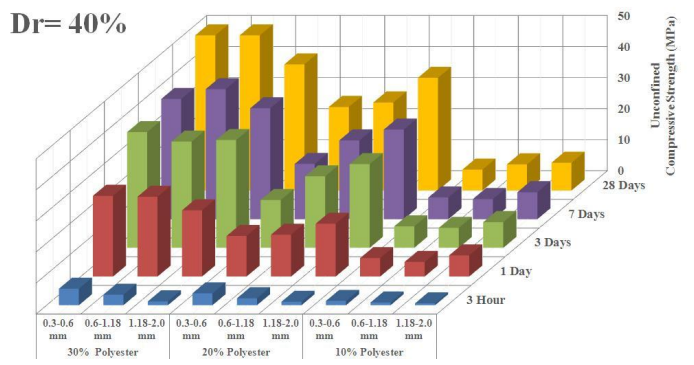

Fig. 3. 3-D column illustration of UCS-Curing period-Polyester ratio of the samples at $40 \%$ relative density with respect to gradation ranges

In terms of sand gradation ranges, it was observed that the coarse sand (i.e., $1.18-2.0 \mathrm{~mm}$ ) samples at $40 \%$ relative density give the maximum UCS values at both $10 \%$ and $20 \%$ polyester ratios (Fig. 3). Similarly, Akbulut et al. [52] reported that UCS 
values increased with an increase in the grain size of the sand. On the other side, at $60 \%$ relative density, there was no general behaviour observed when compared to $40 \%$ relative density (Fig. 4). The maximum UCS values of the samples at $10 \%$, $20 \%, 30 \%$ polyester ratios were obtained as $1.18-2.0 \mathrm{~mm}, 0.3-$ $0.6 \mathrm{~mm}$ and $1.18-2.0 \mathrm{~mm}$, respectively. Additionally, the highest UCS value of this study was obtained from the sample of 0.6$1.18 \mathrm{~mm}$ grain size, $30 \%$ polyester ratios and $40 \%$ relative density. The UCS values of this sample for 3 hours, 1 day, 3 days, 7 days and 28 days curing periods were obtained as 3.4, 25.7, 34.2, 41.9 and 52.3 MPa, respectively (Fig. 3). This different behaviour is also attributed to the fact that the samples become a polyester-sand composite material when $30 \%$ polyester is added to sandy soil. In other words, polyester dominates the behaviour of the samples mixed with $30 \%$ polyester. Following the trends in Figs. 3 and 4, it can be argued that strength increases due to mixing granular soils with polyester approaches an asymptote after $30 \%$.

It is well known that the strength of sandy soils increases by increasing relative density [57,58]. However, it can be seen that the increment of relative density has no effect on the strength of the samples when Fig. 3 and Fig. 4 are examined. Obtaining similar findings with this study, Akbulut and Sağlamer [59] also reported that stabilized loose sandy soils at lower relative densities (i.e., $<60 \%$ relative density) gave higher strength than stabilized dense sandy soils at higher relative densities (i.e., $>60 \%$ relative density) in stabilization applications.

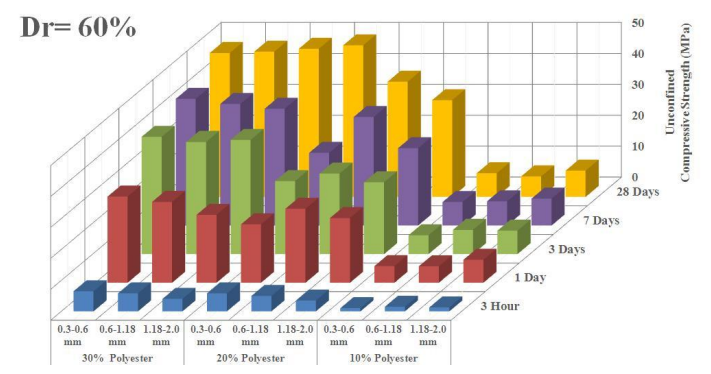

Fig. 4. 3-D column illustration of UCS-Curing period-Polyester ratio of the samples at $60 \%$ relative density with respect to gradation ranges

The deformation behaviour of the highest UCS values' sample and photos of this sample is showed in Fig. 5 and Fig. 6 , respectively. It is clearly seen that the behaviour changes from ductile to brittle deformation when curing period increases from 3 hours to 28 days (Fig. 5). Additionally, the UCS value of the sample (i.e. 0.6-1.18 mm-30\%polyester-Dr: $40 \%$ ) increases up to $52.3 \mathrm{MPa}$ for 28 days curing period. It should be mentioned that the photos of the samples given in Fig. 6 were taken after unconfined compression test. From Fig. 6 it is clear that none of the samples disintegrated and bulged after testing. This rapid and drastic increase in UCS is attributed to rapid cure and adhesion properties of polyester. With a similar manner, researchers found out that the polymers used in their studies increased the unconfined compressive strength for shorter curing periods [41,48]. The reason of this strength increment is consid- ered to be sand particles' forming of a new solid structure with polyester (Fig. 6. The cross-linking of polyester with sand particles (i.e., polyester adheres sand particles) results in this new solid structure. Similar findings were reported by researchers studied both on polymer and polyester [41, 48, 52].

\subsection{The effect of freeze-thaw}

In order to determine the freeze-thaw effect on the samples, a serious experimental study was conducted on 28 days cured samples. The samples were subjected to 20 freeze-thaw cycles. The UCS values of the samples subjected (i.e. 20 cycles) and not subjected (i.e. 0 "zero" cycle) to freeze-thaw cycles are given for 28 days curing period in Fig. 7. It was discovered that the freeze-thaw cycles did not have any effect on the UCS values of the stabilized samples. The reason for this situation is considered to be the durability of polyesters to extraordinary environmental impacts. Similarly, Welling [60] reported that with an increase in the polymer content, the durability of stabilized sandy soils increased. In order to improve the mechanical behaviour of sandy soils, which are exposed to freeze-thaw cycles, polyester can be used as binder material.

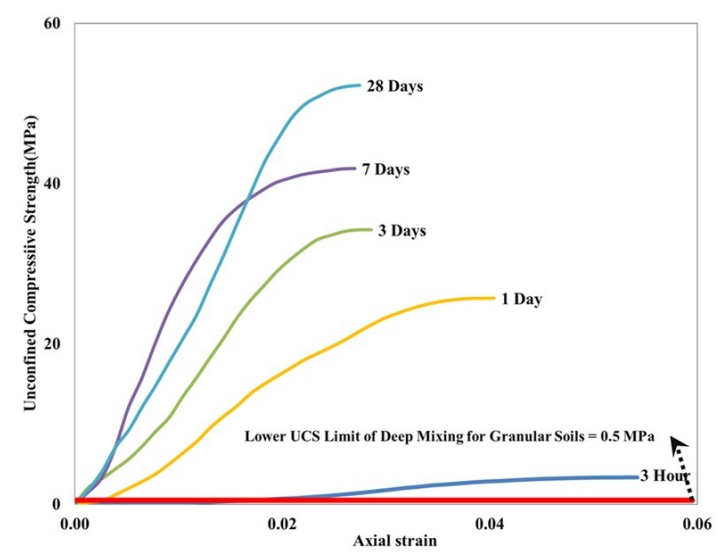

Fig. 5. Deformation behaviour of the highest UCS values' sample (0.6$1.18 \mathrm{~mm}-30 \%$ polyester-Dr=40\%) with curing period

\section{Conclusions}

In this study, in order to investigate the effect of sandy soils stabilized with polyester, unconfined compression tests were performed on the samples. The following conclusions are induced, based on the test results and the discussion presented in this study:

- The UCS values of all samples increased with the increasing polyester ratio.

- The maximum UCS value for 3 hour cured samples was obtained from the sample of $0.3-0.6 \mathrm{~mm}$ at $60 \%$ relative density. The UCS values of this sample for $10 \%, 20 \%$ and $30 \%$ polyester ratios were determined as $1.0,5.8$ and $6.5 \mathrm{MPa}$, respectively.

- There is a significant increase in the UCS values of $20 \%$ and $30 \%$ polyester ratios with an increase on curing periods. 


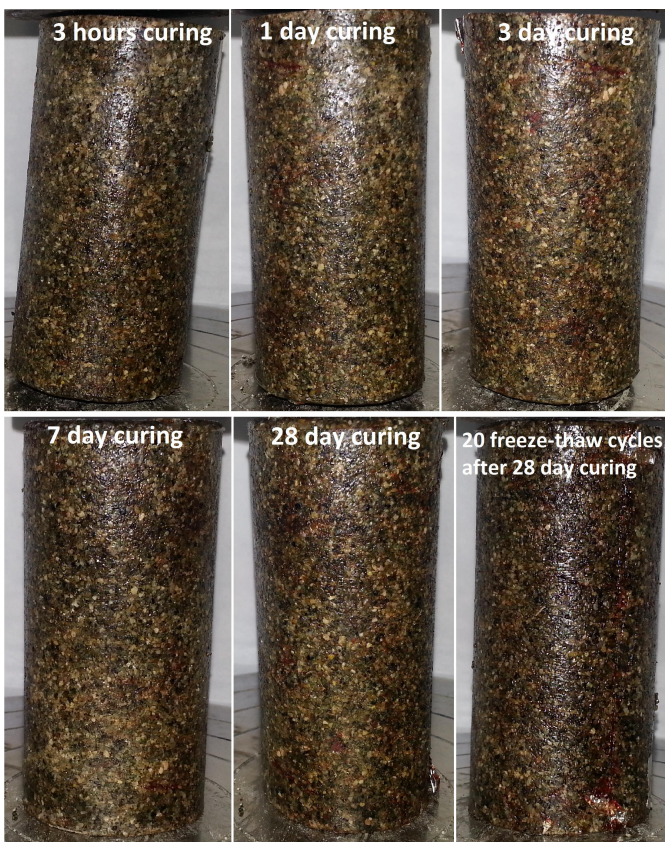

Fig. 6. Photos of the highest UCS values' samples (0.6-1.18 mm-30\% polyester-Dr=40\%) after testing procedure

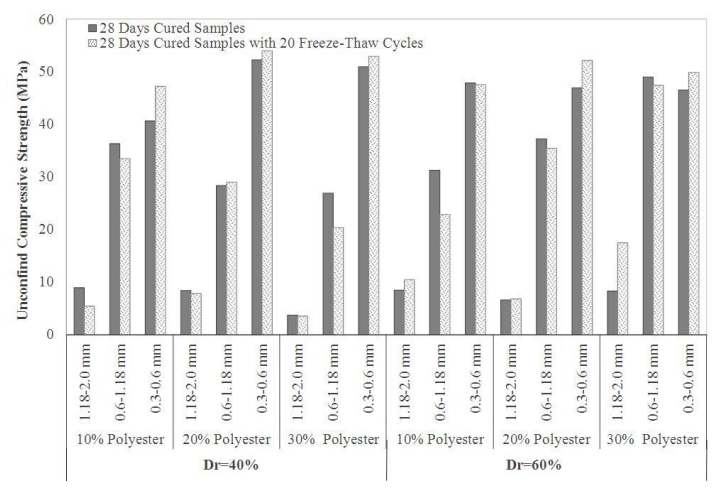

Fig. 7. Effect of freeze-thaw cycles on 28 days cured samples

However, the increase on curing period has no important effect on the UCS values of $10 \%$ polyester samples especially after 1 days curing periods.

- The highest UCS value of this study was obtained from the sample of $0.6-1.18 \mathrm{~mm}$ grain size, $30 \%$ polyester ratio and $40 \%$ relative density. The UCS values of this sample for 3 hours, 1 day, 3 days, 7 days and 28 days curing periods were obtained as 3.4, 25.7, 34.2, 41.9 and $52.3 \mathrm{MPa}$, respectively.

- The UCS values of 3 hours cured samples were higher than those of the suggested lower UCS limit (i.e., 0.5 MPa) of deep mixing. For this reason, polyester can be used for deep mixing applications and for rapid stabilization of soils.

- It was observed that the freeze-thaw cycles did not have any effect on the UCS values of the stabilized samples. It could be said that soil stabilizations to be performed using polyester can also be used as an alternative to cement and lime in the environments prevailed by cold climate and in fields where freeze-thaw is effective.
It can be concluded that polyester may be used in the field applications which need rapid soil stabilization such as slopes that are about to slide. It is recommended that a detailed cost analysis should be made considering the cheapness of cement and lime with respect to polyester.

\section{References}

1 Rafalko S, Filz G, Brandon T, Mitchell J, Rapid Chemical Stabilization of Soft Clay Soils, Transportation Research Record: Journal of the Transportation Research Board, 2026, (2007), 39-46, DOI 10.3141/2026-05

2 Porbaha A, Roblee C, Challenges for Implementation of Deep Mixing in the USA, Proceedings of International Workshop on Deep Mixing Technology, In: In Proceedings of International Workshop on Deep Mixing Technology, 2001.

3 Bruce DA, Bruce MEC, Deep mixing method: A global perspective, In: ASCE Geotechnical Special Publication, Vol. 81, ASCE, 1998, pp. 1-15.

4 Bruce D, Bruce M, The Practitioner's guide to deep mixing, Grouting and Ground Treatment, (2003), 474-488.

5 Terashi M, Kitazume M, Keynote lecture: current practice and future perspective of $Q A / Q C$ for deep-mixed ground, Proceedings of the Deep Mixing, In: Proceedings of the Deep Mixing, 2009, pp. 59-97, DOI 10.1680/grim.2011.164.3.161

6 Terashi M, Kitazume M, QA/QC for deep-mixed ground: current practice and future research needs, Ground Improvement, (2011), 161-177, DOI 10.1680/grim.2011.164.3.161

7 Taki O, Yang DS, Soil-cement mixed wall technique, Geotechnical Engineering Congress, In: American Society of Civil Engineers Proceedings, 1991, pp. 298-309.

8 Glendinning S, Rogers CDF, Deep slope stabilization, using lime piles, Lime Stabilization, (1996), 127-138.

9 Threadgold L, Slope stabilization using reinforced lime piles, Lime Stabilization, (1996), 176-183.

10 Rogers CDF, Glendinning S, Holt CC, Slope stabilization using lime piles-a case study, Proceedings of the ICE - Ground Improvement, 4(4), (2000), 165-176, DOI 10.1680/grim.2000.4.4.165

11 Åhnberg H, Carlsson T, Johansson S-E, Pihl H, Stabilising effects of different binders in some Swedish soils, Proceedings of the ICE - Ground Improvement, 7(1), (2003), 9-23, DOI 10.1680/grim.2003.7.1.9

12 Arasan S, Nasirpur $\mathbf{0}$, The effects of polymers and fly ash on unconfined compressive strength and freeze-thaw behavior of loose saturated sand, Geomechanics and Engineering, 8(3), (2015), 361-375, DOI 10.12989/gae.2015.8.3.361

13 Okumura T, Terashi M, Deep-Lime-Mixing Method of Stabilization for Marine Clays, Proceedings of the 5th Asian Regional Conference on Soil Mechanics and Foundation Engineering, In: Proceedings of the 5th Asian Regional Conference on Soil Mechanics and Foundation Engineering, 1975, pp. 69-75.

14 Terashi M, Tanka H, Ground Improvement by Deep Mixing Method, Proceedings of the Fifth International Conference on Soil Mechanics and Foundation Engineering, In: Proceedings of the Fifth International Conference on Soil Mechanics and Foundation Engineering, 1981, pp. 777-780.

15 Ahnberg $\mathbf{H}$, Stress depend parameters of cement and lime stabilized soils, Proceedings 2nd International Conference on ground Improvement Geosystems-IS, In: Grouting and Deep Mixing; Tokyo, Japan, 1996, pp. 387392.

16 Porbaha A, Tanaka H, Kobayashi M, State of the art in deep mixing technology. Part II: Applications, Proceedings of the ICE - Ground Improvement, 2(3), (1998), 125-139.

17 Porbaha A, Shibuya S, Kishida T, State of the art in deep mixing technol- 
ogy. Part III:geomaterial characterization, Proceedings of the ICE - Ground Improvement, 4(3), (2000), 91-110, DOI 10.1680/grim.2000.4.3.91

18 Bahner EW, Naguib AM, Ground improvement for large above ground petroleum storage tanks using deep mixing, GEODENVER, In: GEODENVER; Denver, Colorado, USA, 2000, pp. 264-280.

19 Jacobson J, Factors affecting strength gain in lime-cement columns and development of a laboratory testing procedure, Master Thesis, Virginia Polytechnic Institute and State University; Virginia, USA, 2002.

20 Miura N, Horpibulsuk S, Nagaraj TS, Engineering behavior of cement stabilized clay at high water content, Soils and Foundations, 41(5), (2002), 33-45, DOI 10.3208/sandf.41.5_33

21 Lorenzo GA, Bergado DT, Fundamental parameters of cemented mixed clay: New approach, Journal of Geotechnical and Geoenvironmental Engineering, 130(10), (2004), 1-9, DOI 10.1061/(ASCE)10900241(2004)130:10(1042)

22 Ratherford CJ, Design manual for excavation support using deep mixing technology, Master Thesis, Texas A\&M University; Texas, USA, 2005.

23 Horpibulsuk S, Miura N, Nagaraj T S, Clay-Water/Cement Ratio Identity for Cement Admixed Soft Clays, Journal of Geotechnical and Geoenvironmental Engineering, 131(2), (2005), 187-192, DOI 10.1061/(ASCE)10900241(2005)131:2(187)

24 Pathivada SP, Effects of water-cement ratio on deep mixing treated expansive clay characteristics, Master Thesis, The University of Texas At Arlington; Texas, USA, 2005.

25 Lorenzo GA, Bergado DT, Fundamental Characteristics of CementAdmixed Clay in Deep Mixing, Journal of Materials in Civil Engineering, 18(2), (2006), 161-174, DOI 10.1061/(ASCE)0899-1561(2006)18:2(161)

26 Maher A, Douglas WS, Yang D, Jafari F, Schaefer VR, Cement Deep Soil Mixing (CDSM) for Solidification of Soft Estuarine Sediments, Marine Georesources \& Geotechnology, 25(3-4), (2007), 221-235, DOI $10.1080 / 10641190701699319$

27 Lewsley G, On the strength of saturated cement-treated soil reconstituted by wet-mixing, Master Thesis, University of British Columbia, 2008.

28 Shrestha R, Soil Mixing: A Study on 'Brusselian Sand' Mixed with Slag Cement Binder, Master Thesis, University of Ghent; Belgium, 2008.

29 Sengör MY, The deformation characteristics of deep mixed columns in soft clayey soils: a model study, Ph.D. Thesis, Middle East Technical University; Ankara, Turkey, 2008.

30 Tang BL, Bakar I, Chan CM, Reutilization of Organic and Peat Soils by Deep Cement Mixing, International Journal of Environmental, Earth Science and Engineering, 5(2), (2011), 12-17.

31 Dias DR, Camarini G, Miguel MG, Preliminary laboratory tests to study the increase of strength in samples of soft soils with cement, for treatments using Dry-Mix System, In: Grouting and Deep Mixing, Vol. 228, ASCE Geotechnical Special Publication, 2012, pp. 454-462.

32 Hartlen J, Holm G, Deep Stabilization of Soft Soils with Lime-Cement Columns, Symposium on Geotechnical Engineering, In: Symposium on Geotechnical Engineering; Singapore, 1995, pp. 173-179.

33 Andromalos KB, Bahner EW, The application of various deep mixing methods for excavation support systems, Grouting and Ground Treatment ASCE, 120, (2004), 515-526.

34 Ahnberg H, Holm G, Stabilization of some Swedish organic soils with different types of binder, Dry mix methods for Deep soil stabilization, (1996), 101-108.

35 Ahnberg H, Strength of stabilized soils-a laboratory study on clays and organic soils stabilized with different types of binder, Ph.D. Thesis, Lund University; Sweden, 2006.

36 Ajorloo AM, Characterization of the mechanical behavior of improved loose sand for application in soil-cement deep mixing, Ph.D. Thesis, University of Lille; France, 2010.

37 Santoni R, Tingle J, Webster S, Stabilization of Silty Sand with Nontradi- tional Additives, Transportation Research Record, 1787, (2003), 33-41, DOI 10.3141/1787-07

38 Newman K, Tingle JS, Emulsion polymers for soil stabilization, FAA Worldwide Airport Technology Transfer Conference, In: FAA Worldwide Airport Technology Transfer Conference; Atlantic City, New Jersey, USA, 2004.

39 Ahmed NB, Chemical stabilization of Baiji sand dunes in Iraq. 1. Effect of some soil stabilizers on the infiltration rate of sand, Qatar University Sci. J., 15(1), (1995), 109-113.

40 Bishop RT, Mcalpin BA, Jones D, Stabilization of earth roads with waterbased polymer emulsions, Proc. S. Afr. Sug. Technol. Ass., 72, (1998), 309315.

41 Al-Khanbashi A, Abdalla SW, Evaluation of three waterborne polymers as stabilizers for sandy soil, Geotechnical and Geological Engineering, 24(6), (2006), 1603-1625, DOI 10.1007/s10706-005-4895-3

42 Gallagher PM, Pamuk A, Abdoun T, Stabilization of Liquefiable Soils Using Colloidal Silica Grout, Journal of Materials in Civil Engineering, 19(1), (2007), 33-40, DOI 10.1061/(ASCE)0899-1561(2007)19:1(33)

43 Gupta SC, Hooda KS, Mathur NK, Gupta S, Tailoring of Guar gum for desert sand stabilization, Indian Journal of Chemical Technology, 16, (2009), 507-512.

44 Naeini SA, Ghorbanalizadeh M, Effect of Wet and Dry Conditions on Strength of Silty Sand Soils Stabilized with Epoxy Resin Polymer, Journal of Applied Sciences, 10(22), (2010), 2839-2846, DOI 10.3923/jas.2010.2839.2846

45 Cabalar AF, Canakci H, Direct shear tests on sand treated with xanthan gum, Proceedings of the ICE - Ground Improvement, 164(2), (2011), 57-64, DOI $10.1680 /$ grim.800041

46 McIntyre J, Synthetic Fibres, Elsevier, 2004, DOI $10.1201 / 9780203501702$

47 Scheirs J, Long TE, Modern polyesters: chemistry and technology of polyesters and copolyesters, John Wiley \& Sons, 2005.

48 Ates E, Optimization of Compression Strength by Granulometry and Change of Binder Rates in Epoxy and Polyester Resin Concrete, Journal of Reinforced Plastics and Composites, 28(2), (2008), 235, DOI 10.1177/0731684407084246

49 Lim SK, Hussin MW, Zakaria F, Ling TC, GGBFS as potential filler in polyester grout: Flexural strength and toughness, Construction and Building Materials, 23(5), (2009), 2007-2015, DOI 10.1016/j.conbuildmat.2008.08.030

50 Jamshidi M, Alizadeh M, Salar M, Hashemi A, Durability of Polyester Resin Concrete in Different Chemical Solutions, Advanced Materials Research, 687, (2013), 150-154, DOI 10.4028/www.scientific.net/AMR.687.150

51 Martínez-Barrera G, Menchaca-Campos C, Gencel O, Polyester polymer concrete: Effect of the marble particle sizes and high gamma radiation doses, Construction and Building Materials, 41, (2013), 204-208, DOI 10.1016/j.conbuildmat.2012.12.009

52 Akbulut RK, Zaimoglu AS, Arasan S, Utilization of unsaturated polyester in improvement of sand with deep mixing method, 5th Geotechnical Symposium, In: 5th Geotechnical Symposium; Cukurova University, Adana, Turkey, 2013. in Turkish with an English summary.

53 Bagherinia M, Utilization of unsaturated polyester in improvement of clays with deep mixing method, Master Thesis, Ataturk University; Turkey, 2013. in Turkish with an English summary.

54 JGS 0821-00: Practice for Making and Curing Stabilized Soil Specimens without Compaction (Translated version), Japanese Geotechnical Society, 2000.

55 EuroSoilStab., Development of design and construction methods to stabilize soft organic soils, EuroSoilStab., 2001. Design Guide Soft Soil Stabilization EC Project BE 96-3177.

56 Zaimoglu AS, Freezing-thawing behavior of fine-grained soils reinforced 
with polypropylene fibers, Cold Regions Science and Technology, 60(1), (2010), 63-65, DOI 10.1016/j.coldregions.2009.07.001

57 Das BM, Advanced soil mechanics, Mc-Grawhill, 1983.

58 Mitchell JK, Soga K, Fundamentals of soil behavior, John Wiley \& Sons, 2005.

59 Akbulut S, Saglamer A, Estimating the groutability of granular soils: a new approach, Tunneling and Underground Space Technology, 17(4), (2002), 371-380, DOI 10.1016/S0886-7798(02)00040-8

60 Welling GE, Engineering performance of polymer amended soils, Master Thesis, The Faculty of California Polytechnic State University; USA, 2012. 